\title{
Drug treatment in the elderly
}

\author{
AMANDA G WARD, M D RAWLINS
}

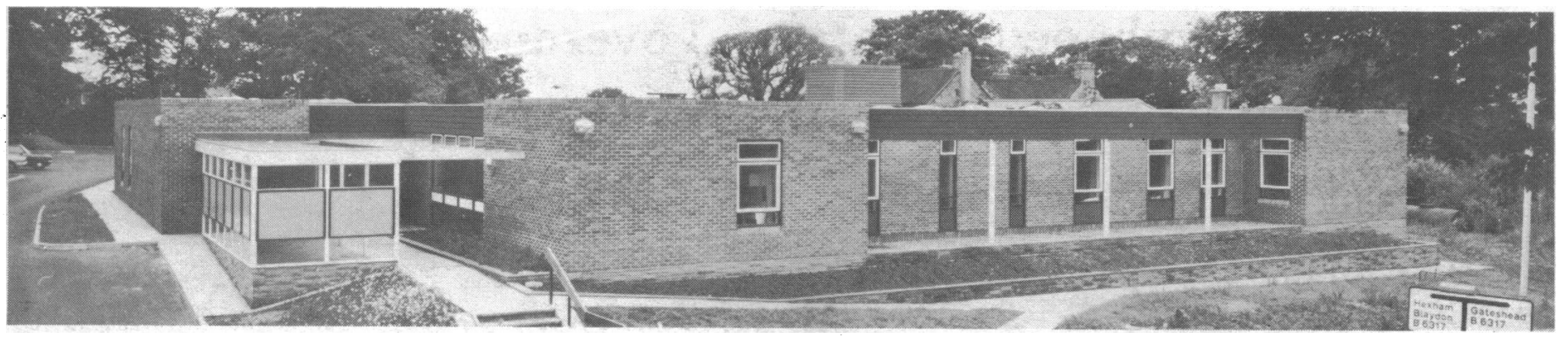

British Medical fournal, 1977, 2, 171

\section{Case history}

Mrs AB, aged 68, moved here three weeks ago to live with her daughter. She has been asthmatic for many years and has been receiving prednisone $(10 \mathrm{mg}$, daily) for the past 15 years. She has also had osteoarthrosis of her knees and hips for nine years and has been taking ibuprofen ( $800 \mathrm{mg}$, thrice daily) for three years. Two months ago she consulted her GP because of a slight tremor of her hands, and because of insomnia. He started her on benzhexol ( $5 \mathrm{mg}$, thrice daily) and nitrazepam (10 mg, nightly) and also gave her a supply of pentazocine to take as necessary for her osteoarthrosis. Since then, she has become increasingly incapable of looking after herself: she has become confused, disorientated, and sometimes hallucinated. Her family felt that she could no longer look after herself, and she has come to live with her daughter. We would like advice on two matters: are her drugs responsible for her recent deterioration; can we rationalise her drug treatment?

\section{Advice}

I saw Mrs AB this morning. She was confused and disorientated in time and space, which the daughter confirmed was a recent development-probably since her "pharmacological assault" six weeks ago. The only abnormal physical signs were in the central nervous system: bilateral nystagmus on lateral gaze, facial immobility, "cog-wheel" rigidity of the right arm, and a definitely ataxic gait.

In view of the temporal relationship between her recent deterioration and her change in drug treatment, as well as the fact that three of her drugs have pronounced psychotropic properties, an iatrogenic basis for her symptoms is probable. But it is also important to consider the possibility of a spaceoccupying lesion in her brain, especially a subdural haematoma. I can't be certain which of her drugs is responsible, and, anyway, pharmacological summation is probably occurring. Both nitrazepam and benzhexol may produce "confusion and disorientation," especially in the elderly. Pentazocine causes

Whickham Health Centre, Whickham, Newcastle upon Tyne AMANDA G WARD, MB, general practitioner

\footnotetext{
Department of Pharmacological Sciences, University of Newcastle upon Tyne, Newcastle upon Tyne NE1 TRU

M D RAWLINS, MD, FRCP, professor of clinical pharmacology
}

hallucination and dysphoria in as many as $20^{\circ}$ of patients, added to which, steroids can produce psychotic reactions in some people.

In the short term I suggest that you should stop the benzhexol, nitrazepam, and pentazocine immediately and carefully observe her progress over the next 48 hours. Perhaps she should be admitted to the cottage hospital, where a closer eye can be kept on her. I don't know whether she needs treatment for her Parkinsonian symptoms: this morning her signs were minimal, and according to her daughter the tremor is much the same as it was before she started benzhexol. Given that her deterioration is drug-induced I would first see whether you can slowly withdraw her oral steroids. She does not appear to have ever tried an inhaled beta-agonist such as salbutamol, and even if this is insufficient in itself I suspect that adding inhaled steroids would probably enable her to be withdrawn entirely from oral steroids.

Secondly, I think that you need to investigate her requirement for analgesic agents for treating her osteoarthrosis. I would start with paracetamol, and add other weak analgesics as necessary-salicylates and a weak opiate (codeine or dihydrocodeine). The night-time pain of osteoarthrosis can often be controlled with indomethacin suppositories. I would not use combination preparations of paracetamol and dihydrocodeine, or paracetamol and salicylate, because you need to retain the freedom to manipulate the dosages and dosage intervals of the constituent analgesics.

It is worth trying to withdraw the oral steroids even at her age because long-term systemic treatment has many long-term adverse effects, apart from suppressing the hypothalamicpituitary axis. Probably the most serious of these are intercurrent infections, osteoporosis, and psychoses.

Some elderly patients respond very adversely to drugs, probably for two reasons. Firstly, certain routes of drug elimination decline with age-particularly renal excretion and hepatic drug oxidation. Secondly, the sensitivity of some target organs increases with age-for example, the control of blood pressure and temperature deteriorate and this type of change might account for some of the enhanced sensitivity.

The real moral is that drug treatment must be instituted with extreme care, using small doses to start, and increasing in the light of the clinical response.

\section{Postscript}

Within 48 hours of stopping benzhexol, nitrazepam, and pentazocine Mrs AB's psychiatric state had improved dramatically. After a week she had recovered almost completely. She is now planning to return to an independent existence. 